\title{
Atributos químicos do solo e lixiviação de compostos fenólicos após adição de resíduo sólido alcalino
}

\author{
Sabrina B. Branco', Cristian B. da Silveira ${ }^{2}$, Mari L. Campos ${ }^{3}$, \\ Luciano C. Gatiboni ${ }^{4}$ \& David J. Miquelluti ${ }^{5}$
}

\begin{abstract}
RESUMO
A utilização de resíduos alcalinos da indústria de papel e celulose (DREGS) na agricultura como corretivo de acidez do solo, vem sendo amplamente empregada como alternativa de descarte no solo de forma a reduzir o impacto ambiental. Objetivou-se, com este trabalho, determinar a influência da aplicação do dregs, rejeito da indústria de papel e celulose, nos atributos químicos do solo e na lixiviação de compostos fenólicos. As unidades experimentais foram constituídas por colunas de lixiviação preenchidas com solo incorporado com dregs nas doses de 0,0; 2,5; 5,0 e 10,0 $\mathrm{g} \mathrm{kg}^{-1}$. Foram realizadas análises químicas nos solos estudados, um Camibissolo Húmico e um Neossolo Quartzarênico, testes de solubilização dos compostos fenólicos e ensaios de lixiviação visando determinar os teores totais de compostos fenólicos presentes nos lixiviados. O uso do dregs modificou os atributos químicos do Cambissolo Húmico e do Neossolo Quartzarênico. Os resultados obtidos nas análises dos lixiviados demonstraram que a aplicação do dregs levou ao incremento de compostos acima do máximo permitido pela legislação vigente, 0,01 $\mathrm{mg} \mathrm{L}^{-1}(\mathrm{ANBR}, 2004 \mathrm{a})$ e de $0,5 \mathrm{mg} \mathrm{L}^{-1}$ (CONAMA, 2008).
\end{abstract}

Palavras-chave: resíduo, dregs, compostos fenólicos, Cambissolo Húmico, Neossolo Quartzarênico

\section{Chemical attributes of soil and leaching of phenolic compounds after addition of alkaline solid residue}

\begin{abstract}
The use of alkaline residues from pulp and paper industry ('dregs') in agriculture as a corrective of soil acidity is being widely used as an alternative of ground disposal in order to reduce the environmental impact. The objective of this study was to determine the influence of application of the 'dregs', waste from pulp and paper industry, in soil chemical properties and leaching of phenolic compounds. The experimental units consisted of leaching columns filled with soil incorporated with 'dregs' at doses of 0, 2.5, 5.0 and $10.0 \mathrm{~g}$ $\mathrm{kg}^{-1}$. Chemical analysis were performed in these soils, a Humic Camibissolo and a Typic Quartzipsamment soils, tests of solubilization of phenolic compounds and leaching tests were also carried out to determine the total content of phenolic compounds present in the leachate. The use of the 'dregs' modified the chemical attributes of the Humic Cambisol and Typic Quartzipsamment. The results obtained in the analysis of the leachate showed that the application of the 'dregs' led to an increase of compounds above the maximum allowed by law, which is 0,01 $\mathrm{mg} \mathrm{L}^{-1}(\mathrm{ANBR}, 2004 \mathrm{a})$ and $0,5 \mathrm{mg} \mathrm{L}^{-1}$ (CONAMA, 2008).
\end{abstract}

Key words: residue, dregs, phenolic compounds, Humic Cambisol, Typic Quartzipsamment 


\section{INTRODUÇÃO}

Atualmente, empresas utilizam o solo como alternativa para o descarte de resíduos domésticos e industriais visando à redução do custo quanto à disposição em aterro sanitário. A baixa acidez do solo é um dos grandes problemas encontrados na agricultura em solos subtropicais. A busca por técnicas eficientes na correção do $\mathrm{pH}$ do solo, associada a um baixo custo, tem sido o grande desafio para os pesquisadores. O mais preocupante é a aplicação desses resíduos na agricultura visto que muitas vezes são comercializados para a correção da acidez do solo ou como fonte de micro e macro-nutrientes para as plantas. Segundo Medeiros et al. (2009) o aproveitamento desses resíduos na agricultura depende de suas características químicas relacionadas aos processos industriais de produção e aos atributos do solo, como $\mathrm{pH}$, quantidade de argila, teores de C orgânico e CTC, entre outros.

O processo de polpação kraft produz um efluente de alta carga orgânica denominado "licor negro", com caráter alcalino (pH aproximadamente 12). O licor negro é queimado para combustão da matéria orgânica e recuperação de produtos químicos gerando um fundido na caldeira, chamando "smelt", que é dissolvido em água, produzindo o licor verde (Teixeira, 2003). A clarificação do licor verde por ocasião da remoção de impurezas, como carbono, partículas de lama, hidróxidos e sulfetos de metais, além de outros elementos, forma um resíduo acinzentado denominado dregs (Almeida et al., 2007) constituído por carbonatos, hidróxidos e sulfetos, sobretudo de $\mathrm{Na}$ e de Ca (Almeida et al., 2008).

De acordo com Almeida et al. (2007) o dregs, por ser composto de carbonatos e sulfatos, teores de $\mathrm{Ca}, \mathrm{Mg}, \mathrm{Na}, \mathrm{K}$, alguns micronutrientes e $\mathrm{pH}$ de aproximadamente 10,7, pode ser usado na correção da acidez de solos agrícolas e também como fonte de cálcio e alguns micronutrientes para as plantas.

Os compostos orgânicos, principalmente os compostos fenólicos, são pouco estudados nos resíduos sólidos industriais. A maioria dos estudos é com os efluentes das indústrias de papel e celulose. Singh et al. (2008) encontraram, em uma análise físico-química do efluente da indústria de papel e celulose, torno de $1440 \mathrm{mg} \mathrm{L}^{-1}$ de fenol total.

Quimicamente, o fenol é um ácido fraco, com $\mathrm{pH}$ de soluções aquosas em torno de 6.0 e reage prontamente com agentes oxidantes, possui um pKa de 10,0 a $25{ }^{\circ} \mathrm{C}(\mathrm{WHO} /$ IPCS, 1994). Em meio alcalino o fenol pode ser convertido em fenolato, o que torna o anel aromático mais reativo devido ao aumento da densidade eletrônica com o par de elétrons adicional do oxigênio (Rodrigues et al., 2010). Os compostos fenólicos são suficientemente resistentes à degradação microbiológica e transportados a longas distâncias pela água (Cunha, 2005). Ainda segundo o autor, causam efeito destrutivo sobre a flora e a fauna aquática devido ao seu potencial tóxico e à alta demanda de oxigênio. Em razão da sua alta toxicidade e persistência no ambiente, tanto a Agência de Proteção Ambiental (EPA) dos EUA quanto a União Europeia têm incluído alguns compostos fenólicos na lista de poluentes prioritários (Santana et al., 2009).

Com o aumento da quantidade de resíduos domésticos e industriais a legislação ambiental se torna mais restritiva. A Resolução do Conselho Nacional do Meio Ambiente n 397/08, (CONAMA, 2008) estabelece que efluentes de qualquer fonte poluidora somente possam ser lançados nos corpos de água, direta ou indiretamente, desde que obedeçam as condições de $0,5 \mathrm{mg} \mathrm{L}^{-1}$ de fenois totais (substâncias que reagem com 4-aminoantipirina). De acordo com a NBR 10004/04 (ABNT, 2004a), que classifica os resíduos sólidos, os fenois são classificados substâncias tóxicas e conferem periculosidade aos resíduos. Com base no exposto, o objetivo do trabalho foi avaliar a influência da adição de resíduo sólido alcalino da indústria de papel e celulose (dregs) nos atributos químicos do solo e na lixiviação de compostos fenólicos.

\section{Material e Métodos}

O estudo foi realizado no Laboratório de Levantamento e Análise Ambiental do Centro de Ciências Agroveterinárias (CAV) da Universidade do Estado de Santa Catarina (UDESC); a amostra de dregs foi coletada de um lote comercializado por uma empresa local; nesta amostra determinou-se sua composição química no Laboratório de Análise do Solo da Universidade Federal do Rio Grande do Sul - UFRGS, conforme Tabela 1.

Tabela 1. Análise química do resíduo alcalino da indústria de papel e celulose (dregs)

\begin{tabular}{lcc}
\hline \multicolumn{1}{c}{ Determinações } & Resultado $^{1}$ & $\begin{array}{c}\text { Limite de } \\
\text { detecção }\end{array}$ \\
Umidade - \% & 50 & - \\
$\mathrm{pH}$ & 12,0 & - \\
Densidade úmida - $\mathrm{kg} \mathrm{m}^{-3}$ & 1149 & - \\
Nitrogênio (TKN) - \% & 0,01 & $0,01 \%$ \\
Potássio total - \% & 0,64 & $0,01 \%$ \\
Cálcio total - \% & 23 & $0,01 \%$ \\
Magnésio total - \% & 1,3 & $0,01 \%$ \\
Enxofre total - \% & 1,5 & $0,01 \%$ \\
Cobre total - mg kg-1 & 123 & $0,6 \mathrm{mg} \mathrm{kg}^{-1}$ \\
Zinco total - mg kg-1 & 256 & $2 \mathrm{mg} \mathrm{kg}$ \\
Sódio total - \% & 6,7 & $10 \mathrm{mg} \mathrm{kg}^{-1}$ \\
Cádmio total - mg kg-1 & 0,5 & $0,2 \mathrm{mg} \mathrm{kg}^{-1}$ \\
Cromo total - \% & 0,18 & $0,4 \mathrm{mg} \mathrm{kg}^{-1}$ \\
Chumbo total - $\mathrm{mg} \mathrm{kg}^{-1}$ & $<2$ & $2 \mathrm{mg} \mathrm{kg}^{-1}$ \\
\hline
\end{tabular}

Análises realizadas no laboratório de análise de solos da Universidade Federal do Rio Grande do Sul (UFRGS)

Para o teste de solubilização foi utilizada a NBR 10006/04 (ABNT, 2004b) com algumas modificações. Com referência à obtenção de extrato solubilizado do resíduo sólido, 250 $\mathrm{g}$ de dregs (resíduo úmido) foram pesados e acrescentada água ultra-pura (Milli-Q) até atingir $1000 \mathrm{~mL}$; as amostras, subdivididas, foram agitadas durante $5 \mathrm{~min}$ em baixa velocidade e deixadas em repouso durante sete dias, em temperatura ambiente; após este período as amostras foram filtradas com auxílio de uma membrana $0,45 \mu \mathrm{m}$ e os teores de compostos fenólicos determinados por espectrofotometria de UV/Vis, em comprimento de onda de $280 \mathrm{~nm}$.

Para o teste de lixiviação foram coletados dois solos: um Cambissolo Húmico $(\mathrm{CH})$, de textura franco-argilosa, em Lages, SC, e um Neossolo Quartzarênico (NQ), de textura areia franca, em Tubarão, SC; após a coleta os solos foram secados em estufa a $60{ }^{\circ} \mathrm{C}$ e passados em peneira com malhas de $2 \mathrm{~mm}$; enfim, as características físico-químicas dos solos estudados são apresentadas na Tabela 2. 
Tabela 2. Características físico-químicas do Camissolo Húmico e do Neossolo Quartizarênico

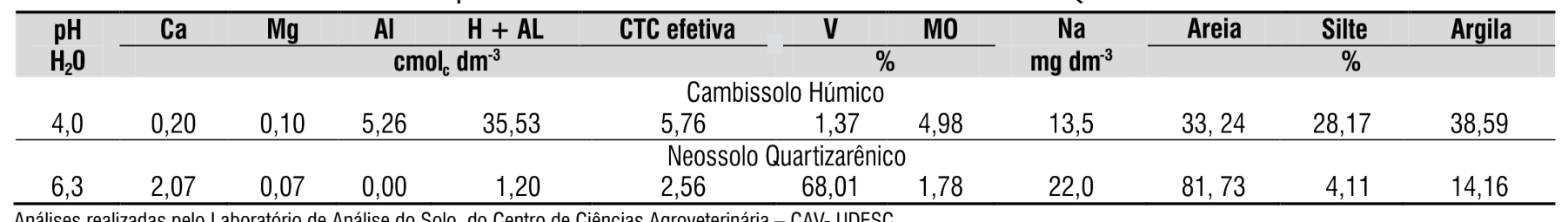

Análises realizadas pelo Laboratório de Análise do Solo, do Centro de Ciências Agroveterinária - CAV- UDESC

Os tratamentos consistiram de quatro doses do resíduo sólido alcalino (dregs), com quatro repetições para cada solo. As unidades experimentais foram constituídas por colunas de lixiviação preenchidas com $500 \mathrm{~g}$ de solo seco incorporado ao dregs. As doses de dregs para o $\mathrm{CH}$ corresponderam à recomendação indicada pelo método SMP, visando atingir pH igual a 6,0 na camada de $0-10 \mathrm{~cm}$ (CQFS-RS/SC, 2005). As doses de dregs incorporadas ao solo foram determinadas a partir do índice SMP inicial do $\mathrm{CH}(4,0)$ cujos tratamentos foram: 0,0 (sem aplicação do resíduo), 2,5 g (1/2 SMP), 5,0 g (1 SMP) e 10,0 g (2 SMP). Para o NQ as doses de dregs incorporadas ao solo foram as mesmas usadas para o $\mathrm{CH}$. Do ponto de vista agronômico o NQ não necessitaria de correção da acidez visto que o $\mathrm{pH}$ do solo sem corretivo era 6,3 ante o que os resultados dos atributos químicos e da lixiviação dos compostos fenólicos do $\mathrm{CH}$ e do NQ foram analisados separadamente uma vez que os dois solos utilizados no experimento apresentam propriedades mineralógicas, físicas e químicas diferentes. Como o dregs utilizado no estudo era úmido e para facilitar sua homogeneização ao solo as amostras foram dissolvidas em 106 e $61 \mathrm{~mL}$ de água destilada para o $\mathrm{CH}$ e NQ, respectivamente. Esses valores foram determinados conforme a capacidade de campo determinada em laboratório; as colunas foram confeccionadas a partir de canos de PVC, com $25 \mathrm{~cm}$ de altura e $5 \mathrm{~cm}$ de diâmetro; a base das colunas foi vedada com uma tampa de PVC, com um orifício na parte central para permitir a drenagem da solução percolada, sobre o qual foi colocado, internamente, papel filtro, a fim de evitar a passagem e a perda de solo durante a lixiviação; a solução percolada foi coletada em frascos plásticos colocados abaixo de cada coluna.

Utilizou-se água destilada para realizar as lixiviações; as amostras foram analisadas após 7, 9, 34, 65 e 99 dias de percolação para o $\mathrm{CH}$ e aos $27,33,47,65$ e 69 dias de percolação para o NQ. O adensamento do solo nas colunas pode ter dificultado a percolação da água, principalmente para o CH, motivo pelo qual as coletas foram realizadas em períodos diferentes; o volume total de água nas lixiviações foi de 530 $\mathrm{mL}$ para o $\mathrm{CH}$ e de $305 \mathrm{~mL}$ para o NQ. Cinco lixiviações foram realizadas, a primeira denominada (L1), a segunda (L2), a terceira (L3), a quarta (L4) e a quinta (L5); as amostras forma retiradas das colunas, secadas ao sol e passadas em peneiras de $2 \mathrm{~mm}$; as análises dos solos das colunas foram realizadas no Laboratório de Análise do Solo, do Centro de Ciências Agroveterinária - CAV- UDESC; as características químicas analisadas foram $\mathrm{pH}-\mathrm{H}_{2} \mathrm{O} ; \mathrm{Na}^{+}\left(\mathrm{mg} \mathrm{dm}^{-3}\right) ; \mathrm{Ca}^{+2}\left(\mathrm{cmol}_{\mathrm{c}} \mathrm{dm}^{-3}\right)$; $\mathrm{Mg}^{+2}\left(\mathrm{cmol}_{\mathrm{c}} \mathrm{dm}^{-3}\right) ; \mathrm{Al}^{+3}\left(\mathrm{cmol}_{\mathrm{c}} \mathrm{dm}^{-3}\right) ; \mathrm{H}^{+}+\mathrm{Al}^{+3}\left(\mathrm{cmol}_{\mathrm{c}} \mathrm{dm}^{-3}\right)$. As concentrações dos compostos fenólicos nas amostras foram determinadas através de um espectrofotômetro UV-Vis (Spekol). A faixa de comprimento de onda empregada para determinação dos compostos fenólicos, foi de $280 \mathrm{~nm}$; quanto à preparação da curva de calibração, utilizou-se o padrão EPA 625 Phenol Mix (Supelco) com as concentrações de 0,0, 0,05, 0,1 e 1,25 ppm em que os dados obtidos foram submetidos à análise de variância e as significativas sofreram ajuste de regressão; já para dados da análise química o ajuste foi pelo programa SAS (2007) e para dados da lixiviação pelo método dos mínimos quadrados ordinários.

\section{Resultados e Discussão}

Quando se comparam os resultados das análises químicas do lote de dregs empregando-se, neste experimento (Tabela 1) com os resultados estudados por outros autores, como Almeida et al. (2007) e Lunardi Neto et al. (2008) percebe-se que cada lote de resíduo comercializado apresenta uma composição química diferente, como os teores de sódio $\left(10,2\right.$ e $\left.34 \mathrm{~g} \mathrm{~kg}^{-1}\right)$, zinco $(235,5$ e $\left.189 \mathrm{~g} \mathrm{~kg}^{-1}\right)$, chumbo $\left(62,9\right.$ e 3,0 $\left.\mathrm{mg} \mathrm{kg}^{-1}\right)$ e cádmio $(5,6$ e 0,9 $\mathrm{mg} \mathrm{kg}^{-1}$ ), respectivamente, entre os outros elementos sendo que aplicações sucessivas deste resíduo podem gerar desequilíbrio nutricional.

O valor encontrado neste experimento de derivados fenólicos totais liberados pelo dregs, foi de aproximadamente $2,43 \mathrm{mg} \mathrm{L}^{-1}$ o valor determinado neste experimento mostra que os compostos fenólicos encontrados no resíduo da indústria de papel e celulose solúveis em água, estão muito acima do permitido pelas resoluções NBR 10004/04 (ABNT, 2004a) e CONAMA (2008). A NBR 1004/04 prevê que o máximo de fenol total em água seja de $0,01 \mathrm{mg} \mathrm{L}^{-1}$ e na Resolução CONAMA no $397 / 08$ o máximo permitido é de $0,5 \mathrm{mg} \mathrm{L}^{-1}$. Este pode ser um indicativo da periculosidade do uso do dregs na agricultura, como corretivo da acidez do solo.

A presença desses compostos no dregs pode ser atribuída à degradação química da lignina que produz compostos fenólicos (Wahyudiono \& Motonobu, 2008). As ligninas Kraft são subprodutos do licor negro (Wallberg et al., 2005), produzido na polpação Kraft, sofrem hidrólise parcial de grupos $\mathrm{OH}$ fenólicos, o que provoca um aumento dos valores médios de absorbância relativa de grupos hidroxila e apresentam elevado teor de grupos $\mathrm{OH}$ fenólicos e baixo $\mathrm{OCH}_{3}$ (Nada et al., 1998).

Como observado nas Figuras 1A e 1B, com o aumento das doses de dregs, 0,$0 ; 2,5 ; 5,0$ e $10,0 \mathrm{~g} \mathrm{~kg}^{-1}$, o valor do $\mathrm{pH}$ aumentou linearmente (Figura 1A) e a acidez potencial diminuiu quadraticamente (Figura 1B) para o CH. Este comportamento era previsto de vez que o dregs é um resíduo alcalino.

Os resultados encontrados para o aumento do $\mathrm{pH}$ do solo e consequentemente a diminuição da acidez potencial, corroboram com outros trabalhos utilizando-se o dregs como corretivo da acidez do solo (Teixeira, 2003; Almeida et al., 2008; Medeiros et al., 2009). O aumento do $\mathrm{pH}$ do solo pode ser atribuído à 

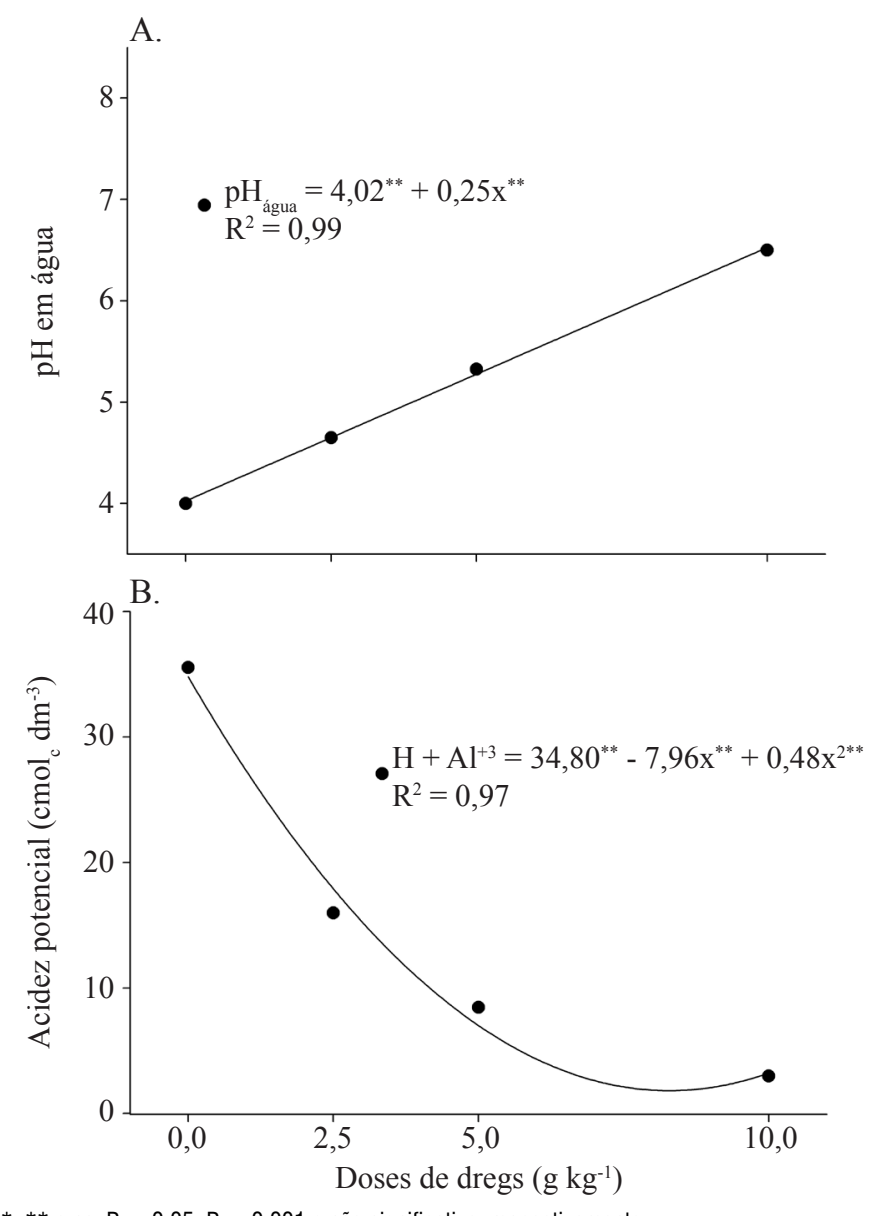

*, ${ }^{* *}$ e ns: $P<0,05 ; P<0,001$ e não significativo, respectivamente

Figura 1. Regressões para $\mathrm{pH}$ em água (A) e acidez potencial (B) de um Cambissolo Húmico incorporados com doses $(x)$ de dregs

elevada quantidade de carbonatos e hidróxidos responsáveis pelo alto valor de neutralização do resíduo (Almeida et al., 2007), motivo da utilização deste resíduo no solo.

Para o teor de $\mathrm{Na}^{+}$trocável, percebe-se um aumento linear neste valor com o aumento da dose de dregs para o $\mathrm{CH}$ (Figura 2A). $\mathrm{O}$ íon $\mathrm{Na}^{+}$apresenta um elevado raio hidratado e possui dificuldade de se aproximar das partículas sólidas do solo carregado negativamente. Desta forma, teores muito elevados de $\mathrm{Na}^{+}$no solo podem diminuir a permeabilidade à água e ao ar, alterando algumas propriedades do solo pela dispersão dos coloides que podem afetar algumas propriedades físicas do solo (Almeida et al., 2007; Medeiros et al., 2009) o que também pode ter influenciado na percolação da água nas colunas preenchidas com o $\mathrm{CH}$. A concentração de $\mathrm{Na}^{+}$no dregs, $67 \mathrm{~g} \mathrm{~kg}^{-1}$ (Tabela 1), encontrada neste experimento, foi superior à encontrada por Almeida et al. (2007) e Lunardi Neto et al. (2008) que encontraram 10,2 e $34 \mathrm{~g} \mathrm{~kg}^{-1}$, respectivamente. As deficiências nos processos de lavagem e remoção dos produtos químicos do dregs, assim como falhas no sistema de filtração, podem acarretar descarte de material com alto teor de sódio, criando problemas para sua aplicação na agricultura (Teixeira, 2003).

As concentrações de $\mathrm{Ca}^{+2}$ e $\mathrm{Mg}^{+2}$ trocáveis aumentaram quadraticamente para o $\mathrm{CH}$, como observado nas Figuras 2B e $2 \mathrm{C}$, respectivamente. $\mathrm{O}$ aumento do $\mathrm{Ca}^{+2}$ está diretamente relacionado à composição química do dregs, que é composto principalmente por carbonatos (Almeida et al., 2007) apresentando elevado teor de $\mathrm{Ca}^{+2} 230 \mathrm{~g} \mathrm{~kg}^{-1}$ (Tabela 1). $\mathrm{O}$ teor de $\mathrm{Ca}^{+2}$ passou de $0,20 \mathrm{cmol}_{\mathrm{c}} \mathrm{dm}^{-3}$ para $16,35{\mathrm{cmolc} \mathrm{dm}^{-3} \mathrm{na}}^{-1}$ maior dose $\left(10,0 \mathrm{~g} \mathrm{~kg}^{-1}\right)$. Apesar de ter elevado a concentração de $\mathrm{Mg}^{+2}$ (Figura 2C), no solo em função do aumento das doses de dregs, o teor ainda se encontra abaixo do nível crítico, que é de $0,5 \mathrm{cmol}_{\mathrm{c}} \mathrm{kg}^{-1}$ (CQFS-RS/SC, 2004) passível de causar deficiência deste elemento devido ao desequilíbrio catiônico promovido pela utilização do dregs como corretivo ou fornecedor de nutrientes como o $\mathrm{Mg}^{+2}$.

Para a relação $\mathrm{Ca} / \mathrm{Mg}$ ocorreu um aumentando quadrático, como observado na Figura 2D. As alterações nas quantidades e proporções de $\mathrm{Ca}^{+2} \mathrm{e} \mathrm{Mg}^{+2}$ trocáveis modificam a concentração desses cátions na solução do solo, o aumento da relação $\mathrm{Ca} /$ $\mathrm{Mg}$ é prejudicial, causando desbalanço nutricional uma vez que o dregs apresenta elevada relação $\mathrm{Ca} / \mathrm{Mg}$, podendo inibir a absorção de $\mathrm{Mg}^{+2}$ (Albuquerque et al., 2011).

$\mathrm{Na}$ Figura 3 são apresentadas as regressões para as doses de dregs aplicadas no Cambissolo Húmico em função das concentrações de compostos fenólicos lixiviados; percebe-se um aumento linear na concentração de compostos fenólicos com o aumento das doses de dregs incorporadas ao solo; este aumento na concentração de compostos fenólicos pode ser atribuído à quantidade de lignina kraft remanescente do licor negro, que apresenta compostos fenólicos em sua composição e pode estar presente na composição do dregs. Quando somados ao encontrado naturalmente no solo, esses compostos contribuem para o aumento desses compostos no lixiviado.

Costa et al. (2009) encontraram, em estudo com lodo da estação de tratamento de uma fábrica de papel reciclado, na água de percolação concentrações de fenois acima do permitido, para dois solos (Cambissolo e Neossolo), com efeito significativo apenas entre os dois tipos de solo, não sendo encontrada diferença estatística para as doses crescentes nem para a interação das doses com os tipos de solo. Neste experimento os resultados mostram que houve aumento significativo das concentrações de compostos fenólicos com o aumento das doses crescentes de dregs aplicadas ao solo porém, quando comparada com as lixiviações L1, L2, L3, L4 e L5, não ocorre diferença estatística entre elas, conforme a Figura 3.

A presença de compostos fenólicos na amostra sem aplicação do resíduo (dose 0,0$)$, pode ser atribuída à decomposição da matéria orgânica presente no solo.

$\mathrm{Na}$ lixiviação 5 o incremento de compostos fenólicos foi de 2 vezes em relação à lixiviação 1 , mesmo não sendo estatisticamente diferente. Este incremento pode ser atribuído à geração de cargas negativas, com o aumento do $\mathrm{pH}$ do solo pela aplicação do dregs. De acordo com Trigueiro (2006) à medida em que se elevaram as doses de dregs e grits os teores no solo aumentaram os teores no solo de $\mathrm{Na}^{+}, \mathrm{K}^{+}, \mathrm{Ca}^{+2}$ , $\mathrm{Mg}^{+2} \mathrm{e} \mathrm{pH}$; ainda segundo o autor, o teor de matéria orgânica (MO) diminuiu com a aplicação dos resíduos, o que pode ser atribuído à decomposição da $\mathrm{MO}$ remanescente influenciada pelo aumento do $\mathrm{pH}$. Além disto, a adição de elementos inorgânicos ao solo pode competir pelos sítios de adsorção. Os íns em solução interagem com a fase sólida do solo formando diferentes complexos que afetam sua adsorção e/ou mobilidade (Luchese et al., 2008). 


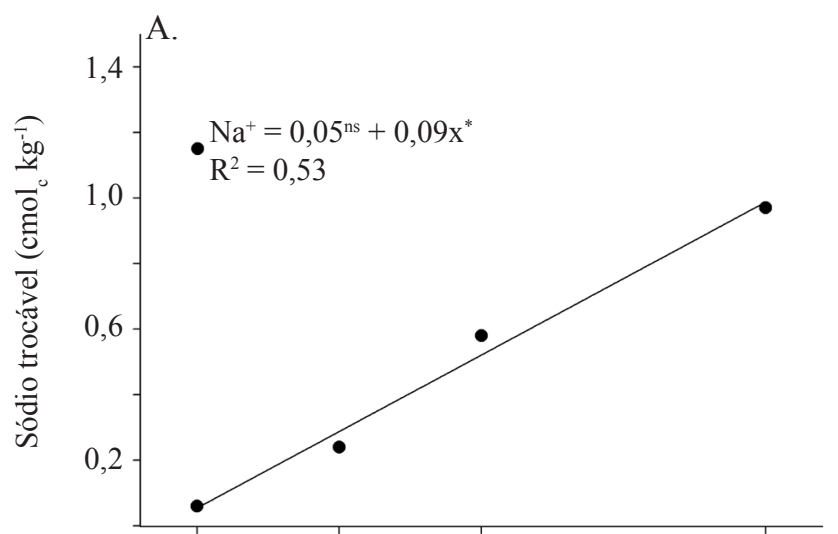

B.

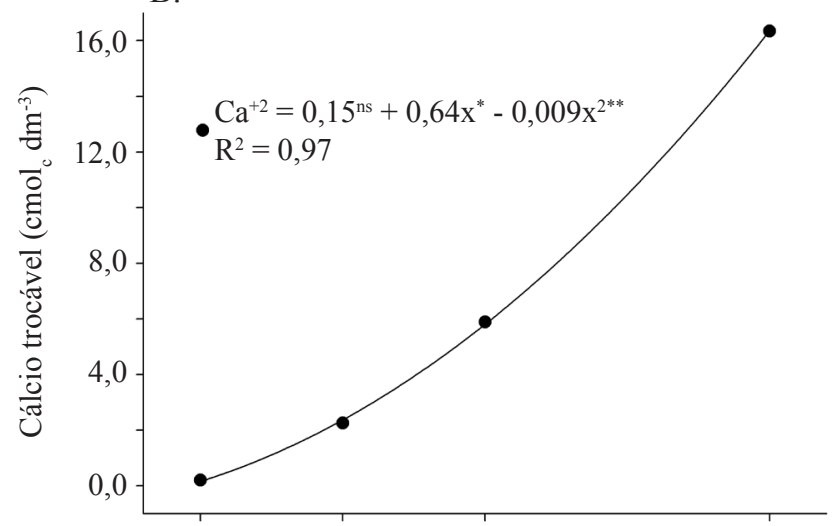

C.
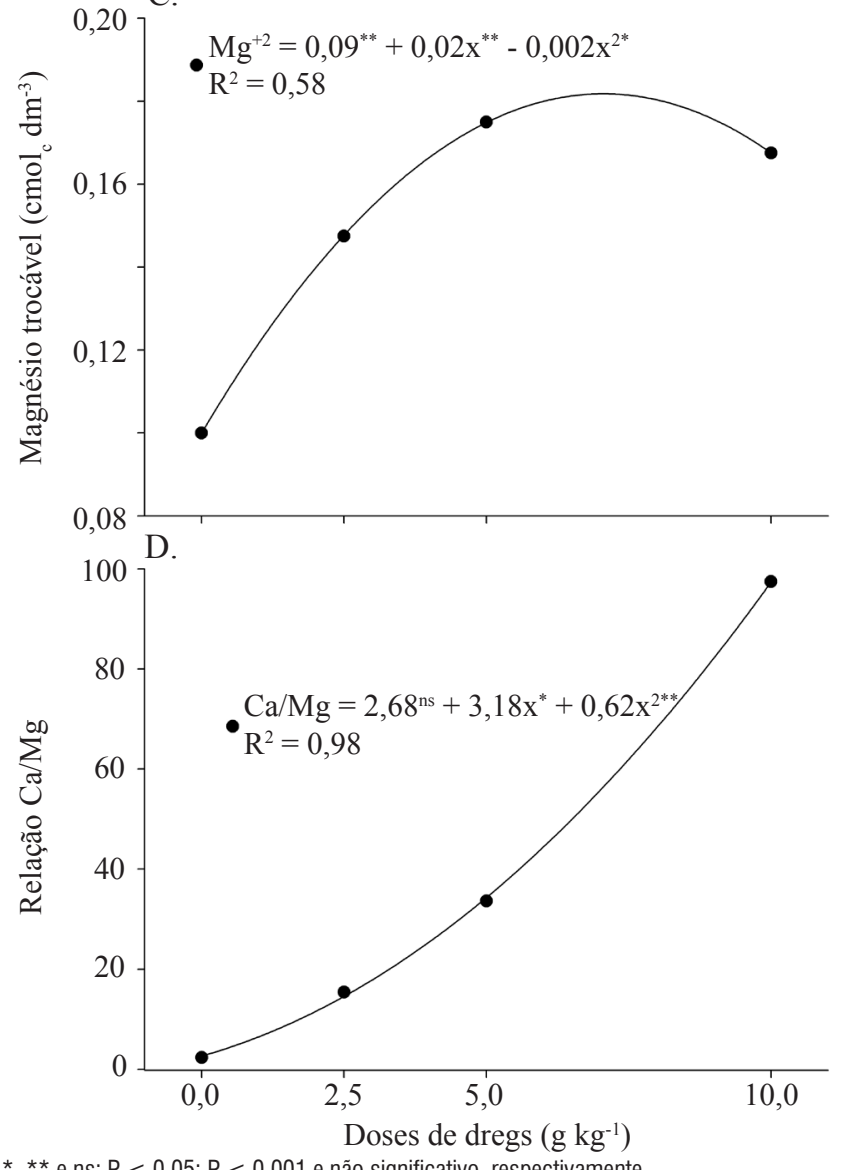

P $<0,001$ e não significativo, respectivamente

Figura 2. Regressões para $\mathrm{Na}^{+}(\mathrm{A}), \mathrm{Ca}^{+2}(\mathrm{~B}) \mathrm{Mg}^{+2}(\mathrm{C}) \mathrm{e}$ $\mathrm{Ca} / \mathrm{Mg}(\mathrm{D})$ de um Cambissolo Húmico incorporados com doses $(\mathrm{x})$ de dregs

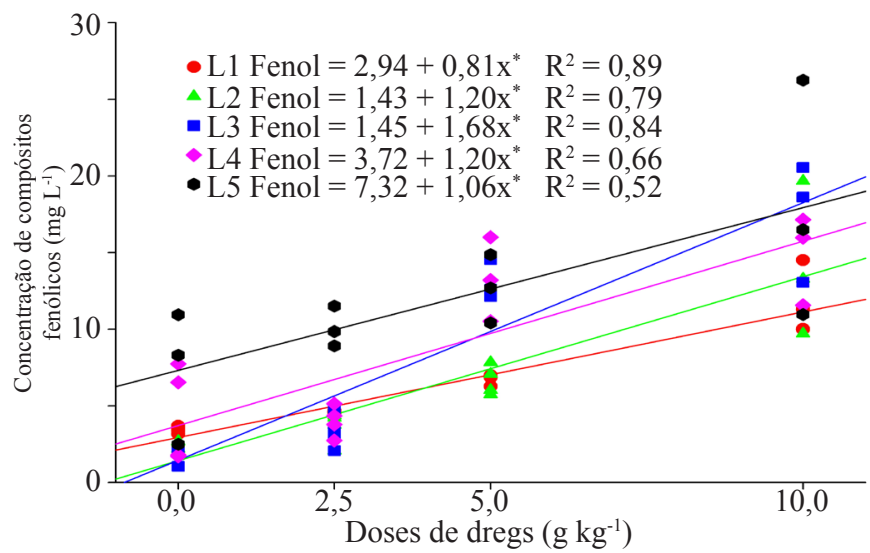

* e ns: significativo a P, 0,05 e não significativo, respectivamente. L1, L2, L3, L4 e L5 representam lixiviações realizadas referente as doses de dregs de $0,2,5,5,0$ e 10,0 $\mathrm{g} \mathrm{kg}^{-1}$

Figura 3. Ajuste de regressões para a concentração de compostos fenólicos de um Cambissolo Húmico com doses $(\mathrm{x})$ crescentes de dregs

Outro fator que pode estar contribuindo para o aumento da concentração dos compostos fenólicos é a repulsão do íon fenolato. Como o pKa do fenol é de 10,0, ou seja, $50 \%$ fenol e $50 \%$ fenolato, a pH 6,5 (maior dose de dregs $10,0 \mathrm{~g} \mathrm{~kg}^{-1}$ ) existe uma concentração do íon fenolato em solução que sofre repulsão por estar na sua forma aniônica, como o $\mathrm{CH}$ apresenta uma CTC de 5,76 $\mathrm{cmol}_{\mathrm{c}} \mathrm{dm}^{-3}$, teor de MO de 4,98\% e argila de $38,49 \%$ (Tabela 2) este solo possui cargas negativas que repelem esses compostos enquanto as espécies de fenol que não estão na sua forma aniônica devem ter sido adsorvidas pelas argilas. Segundo Cavalcanti et al. (2009) o decréscimo do $\mathrm{pH}$ favoreceu ligeiramente a adsorção do fenol em argilas organofílicas deslocando naturalmente o equilíbrio para a adsorção favorecendo a interação superficial argila/fenol.

Apesar de haver aumento da concentração dos compostos fenólicos com a aplicação do dregs, não há diferença estatística entre as lixiviações do $\mathrm{CH}$ (Figura 10). Este comportamento pode ser atribuído à percolação preferencial da água pelas paredes das colunas de lixiviação e dispersão das argilas. Ensaios conduzidos em colunas de lixiviação podem apresentar fluxo preferencial de água e compostos pelas paredes das colunas, induzidos pela formação desses caminhos durante a montagem da coluna (Mariot et al., 2009). A dispersão das argilas pode ser promovida pelo aumento do $\mathrm{pH}$ e pela alta concentração de $\mathrm{Na}^{+}$presentes no dregs, levando ao entupimento dos poros dificultando, assim, a percolação da água; por outro lado, na montagem do experimento a estrutura natural do $\mathrm{CH}$ foi destruída pelo processo de moagem o que facilitou a dispersão das argilas, afetando as lixiviações e fazendo com que o tempo de percolação da água fosse maior.

A capacidade de sorção de fenois pode ser atribuída ao elevado conteúdo de matéria orgânica, propiciando a decomposição dos fenois em enzimas e polímeros que entram na formação das moléculas de ácidos húmicos e fúlvicos (Pacheco Júnior et al., 2005). O Cambissolo Húmico apresenta uma quantidade de MO 4,98\% o que também pode ter influenciado na adsorção desses compostos e na sua lixiviação.

Com o objetivo de verificar a influência da aplicação do dregs nas propriedades químicas: $\mathrm{pH}-\mathrm{H}_{2} \mathrm{O} ; \mathrm{Na}^{+}\left(\mathrm{mg} \mathrm{dm}^{-3}\right) ; \mathrm{Ca}^{+2}$ $\left(\mathrm{cmol}_{\mathrm{c}} \mathrm{dm}^{-3}\right) ; \mathrm{Mg}^{+2}\left(\mathrm{cmol}_{\mathrm{c}} \mathrm{dm}^{-3}\right) ; \mathrm{Al}^{+3}\left(\mathrm{cmol}_{\mathrm{c}} \mathrm{dm}^{-3}\right) ; \mathrm{H}^{+}+\mathrm{Al}^{+3}$ 
$\left(\mathrm{cmol}_{\mathrm{c}} \mathrm{dm}^{-3}\right)$, de um Neossolo Quartzarênico (NQ) as doses utilizadas neste solo foram as mesmas usadas para o Cambissolo Húmico $(\mathrm{CH})$, apesar do NQ ter apresentado um pH 6,3 nas amostras sem aplicação do resíduo.

Nas Figuras 4A e 4B são observados os efeitos da aplicação de dregs no $\mathrm{pH}$ e na acidez potencial $(\mathrm{H}+\mathrm{Al})$ para o NQ. Com o aumento das doses de dregs de 0 para $10,0 \mathrm{~g} \mathrm{~kg}^{-1}$, o pH aumentou quadraticamente (Figura 4A) e a acidez potencial $(\mathrm{H}+\mathrm{Al})$ diminuiu quadraticamente (Figura 4B). De acordo com Trigueiro (2006) o aumento do $\mathrm{pH}$ está relacionado com a diminuição da acidez potencial proporcionada pelo aumento da dose do resíduo. Resíduos alcalinos possuem maior eficiência na correção da acidez do solo, em função da quantidade de $\mathrm{NaOH}$ e $\mathrm{Ca}(\mathrm{OH})_{2}$ em sua composição, os quais liberam hidroxilas $\left(\mathrm{OH}^{-}\right)$possuindo maior solubilidade que o calcário (Corrêa et al., 2007).
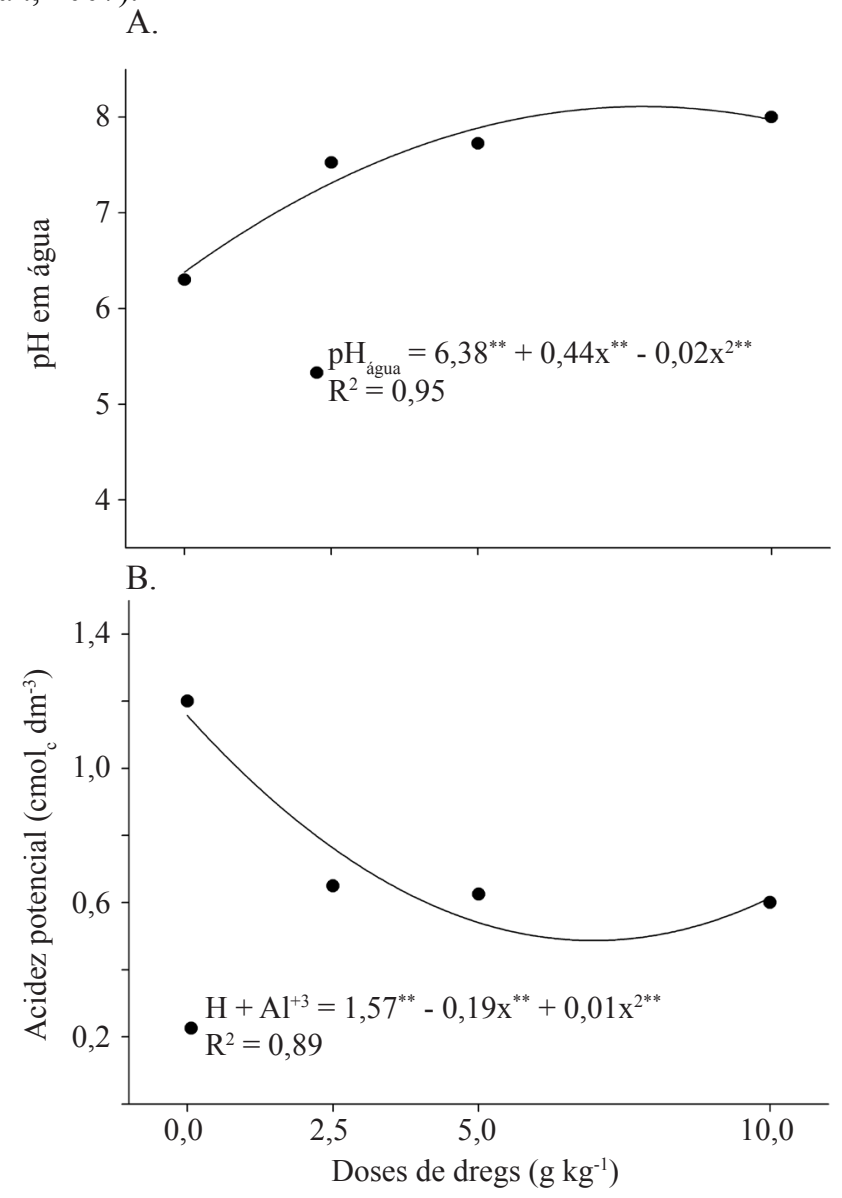

* , ** e ns: significativo a $\mathrm{P}<0,05,<0,01$ e não significativo, respectivamente

Figura 4. Regressões para $\mathrm{pH}$ em água (A) e acidez potencial $(\mathrm{H}+\mathrm{Al})(\mathrm{B})$ de um Neossolo Quartzarênico incorporados com doses $(x)$ de dregs

Com a aplicação das doses crescentes de dregs ao solo houve um aumento linear do teor de $\mathrm{Na}^{+}$trocável, conforme observado na Figura 5A. Lunardi Neto (2008) e Almeida et al. (2007) encontram em torno de 3,4 e $1 \% \mathrm{de}^{\mathrm{Na}^{+}}$no dregs, respectivamente, valores inferiores aos encontrados no dregs utilizado neste estudo de $6,7 \%$; conforme discutido anteriormente, pode haver diferença de concentração de $\mathrm{Na}^{+}$ para cada lote de dregs. A adição, ao solo, de materiais com alta concentração de $\mathrm{Na}^{+}$pode provocar efeitos adversos e
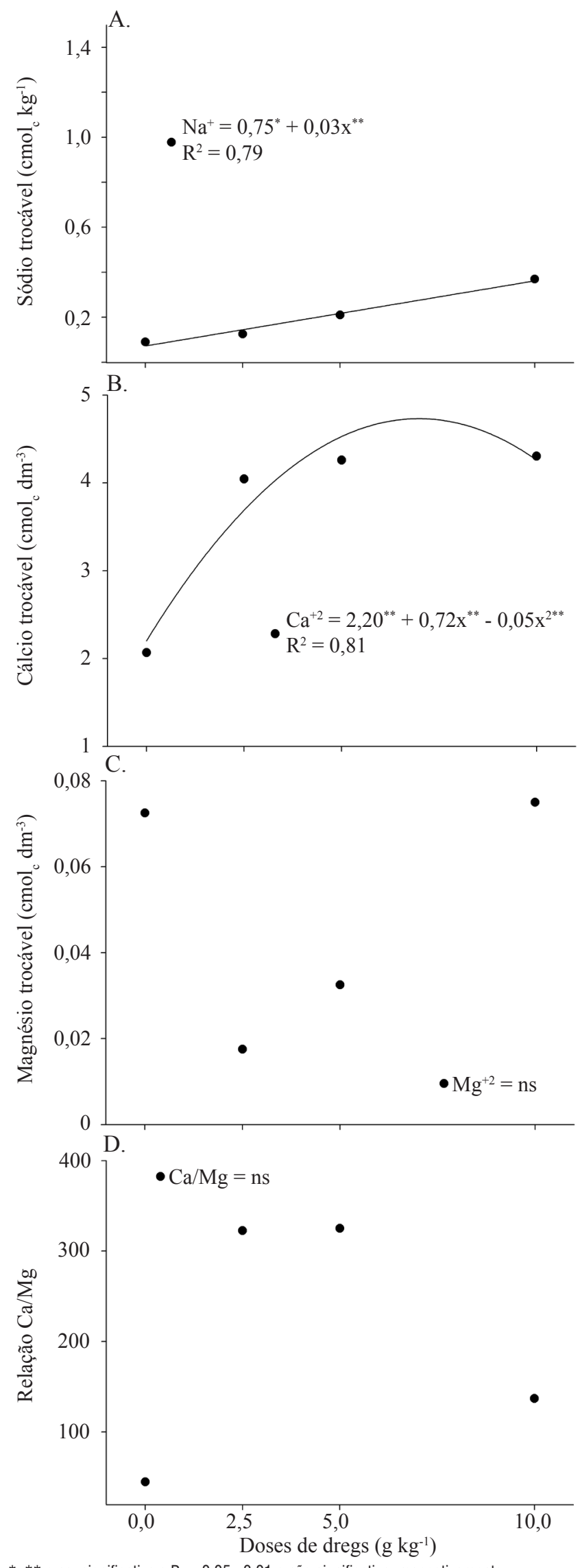

* , * e ns: significativa a $\mathrm{P}<0,05 ; 0,01$ e não significativo, respectivamente

Figura 5. Regressões para $\mathrm{Na}^{+}(\mathrm{A}), \mathrm{Ca}^{+2}(\mathrm{~B}), \mathrm{Mg}^{+2}$ (C) e Ca/Mg (D) de um Neossolo Quartzarênico incorporadas com doses $(\mathrm{x})$ de dregs 
indiretos (Teixeira, 2003) afetando o processo de agregação do solo e a formação de selo superficial quando o solo é utilizado para descarte de resíduos (Albuquerque et al., 2002). Resíduos com altos teores de sódio e cálcio, como o dregs e grits, aplicados em solos com textura arenosa, são mais suscetíveis a lixiviação do sódio no perfil do solo podendo contaminar as águas subterrâneas (Trigueiro, 2006). Como o NQ apresenta uma CTC de 2,56 $\mathrm{cmol}_{\mathrm{c}} \mathrm{dm}^{-3}$, com poucas cargas negativas, o uso de resíduos em solos arenosos deve ser feito com cuidados adicionais haja vista que a fração biodisponível dos metais, ou seja, o que está na solução do solo e prontamente disponível para as plantas e aos micro-organismos pode ser maior que em solos argilosos (CQFS-RS/SC, 2004).

A concentração de $\mathrm{Ca}^{+2}$ trocável aumentou quadraticamente para o NQ (Figura 5B) e o teor de $\mathrm{Mg}^{+2}$ não teve efeito significativo (Figura 5C). Como o dregs possui, em sua composição, alto teor de $\mathrm{Ca}^{+2} 230 \mathrm{~g} \mathrm{~kg}^{-1}$ (Tabela 1) e há preferência dos sítios de adsorção pelo $\mathrm{Ca}^{+2}$, este pode forçar o deslocamento do $\mathrm{Mg}^{+2}$, além da formação de pares iônicos com outros elementos contidos no resíduo (Medeiros et al., 2009), podendo causar deficiência de $\mathrm{Mg}^{+2}$, em virtude do dregs ser composto principalmente por carbonatos, hidróxidos e sulfetos de sódio e cálcio (Almeida et al., 2007). Para a relação Ca/ $\mathrm{Mg}$ o efeito não foi significativo (Figura 5D) em razão das características deste solo, como baixa CTC.

$\mathrm{Na}$ Figura 6 são apresentados os resultados com as regressões para as doses de dregs aplicadas no NQ em função das concentrações de compostos fenólicos no lixiviado. Com o aumento das doses de dregs incorporadas ao solo observa-se um aumento linear na concentração dos derivados fenólicos presentes no lixiviado.

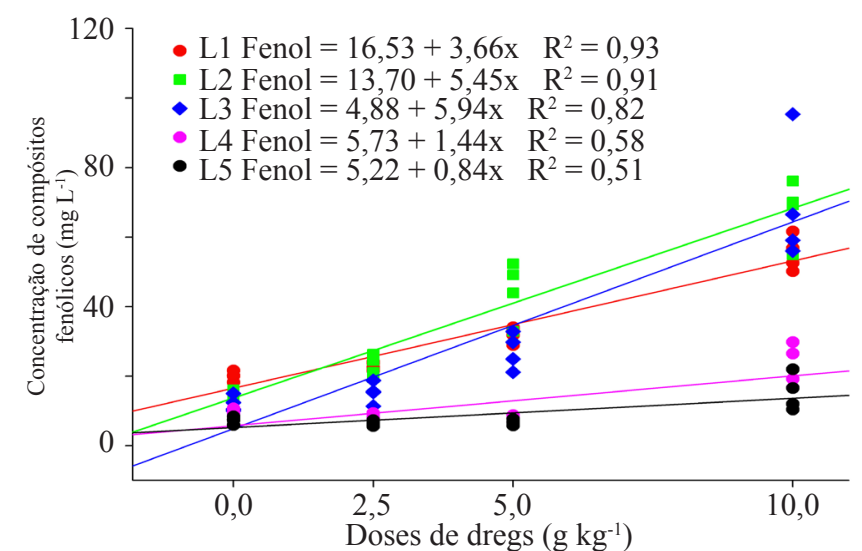

* e ns: significativo a $\mathrm{P}<0,05$ e não significativo, respectivamente. L1, L2, L3, L4 e L5 representam lixiviações realizadas referente as doses de dregs de 0, 2,5, 5,0 e 10,0 g kg-1

Figura 6. Ajuste de regressões para a concentração de compostos fenólicos de um Neossolo Quartzarênico (b) com doses $(\mathrm{x})$ crescentes de dregs

Os dados obtidos mostram que ocorre maior concentraçao de compostos fenólicos nas primeiras 3 lixiviações diminuindo, porém, nas duas últimas, comportamento este já previsto, de vez que referido solo possui poucas cargas e baixo conteúdo de matéria orgânica.

O NQ apresenta uma CTC efetiva de 2,56 $\mathrm{cmol}_{\mathrm{c}} \mathrm{dm}^{-3} \mathrm{e}$ baixa quantidade de matéria orgânica (MO), cerca de 1,78\%; a menor quantidade de carga superficial e a menor concentração de matéria orgânica influenciam diretamente na adsorção dos compostos fenólicos aumentando, desta forma, a concentração desses compostos no lixiviado.

Além do mais, o NQ apresenta uma macroporosidade maior, o que facilita a lixiviação diminuindo o tempo de percolação da água nesses solos. De acordo com Pinheiro et al. (2011) pesticidas submetidos aos processos de degradação e sorção nas partículas do solo são transportados na direção vertical pela água percolada e as quantidades transportadas serão mais expressivas se a percolação ocorrer em caminhos preferenciais, formados pelos macroporos.

Outro fator que pode estar influenciando a lixiviação dos compostos fenólicos é o do pH do solo que, antes da aplicação do dregs, na dose zero, já era de aproximadamente 6,3, muito mais alcalino que o $\mathrm{CH}$. Em meios fortemente alcalinos o fenol é convertido para fenolato, que é sua forma aniônica, possuindo um pKa de 10,0, ou seja, $50 \%$ fenol e $50 \%$ fenolato. A pH 8,0 (maior dose de dregs $10,0 \mathrm{~g} \mathrm{~kg}^{-1}$ ) existe uma presença maior de fenolato em solução aumentando o efeito repulsivo associado à baixa CTC deste solo, fato evidenciado pelas perdas dos compostos fenólicos já nas primeiras lixiviações. A capacidade de sorção de fenois diminui com o aumento de $\mathrm{pH}$ devido as forças repulsivas entre a carga superficial da caulinita e o caráter aniônico dos fenois (Pacheco Júnior et al., 2005). Calace et al. (2002) em estudo com lodo da indústria de papel e celulose para remover fenois em águas residuais, observaram que em $\mathrm{pH}$ 8,0 os silicatos presentes no lodo têm sua superfície carregada negativamente, o que envolve forças repulsivas com o íons fenolato e cujas forças dificultam a sorção desses íons. Ainda de acordo com os autores, as principais características químicas de fenois que desempenham papel importante no mecanismo de sorção são a solubilidade e o pKa. Além disto, a molécula de fenol apresenta alta solubilidade em água devido à presença de grupos hidroxilas e sua inserção no meio fará com que os fenois com seus grupos $\mathrm{OH}^{-}$tomem parte da migração dos grupos $\mathrm{OH}^{-}$resultantes do processo eletrolítico da água (Silva \& Assis, 2004).

\section{ConclusõES}

1. A aplicação do dregs aumenta o pH, o teor de cálcio e sódio e diminui o teor de alumínio e acidez potencial; para o $\mathrm{CH}$, elevou a relação $\mathrm{Ca} / \mathrm{Mg}$, o que pode levar à deficiência em solos com baixo teor de magnésio.

2. Para cada lote comercializado deve-se realizar análises químicas, a fim de evitar qualquer prejuízo ao balanço nutricional do solo.

3. Os resultados encontrados no teste de solubilização indicam a presença de compostos fenólicos na amostra de dregs analisada.

4. O aumento da quantidade aplicada de dregs levou ao incremento de compostos fenólicos no lixiviado do Neossolo Quartzarênico, principalmente até a terceira lixiviação.

5. A presença de compostos fenólicos sugere estudos mais detalhados, como a cromatografia, visando identificar e quantificar os compostos fenólicos encontrados no resíduo gerado pela indústria do papel e celulose. 


\section{Literatura Citada}

ABNT - Associação Brasileira de Normas Técnicas: NBR 10004: Resíduos sólidos - classificação. Rio de Janeiro: ABNT, 2004a. 71p.

ABNT - Associação Brasileira de Normas Técnicas. NBR 10006: Procedimento para obtenção de extrato solubilizado de resíduos sólidos. Rio de Janeiro: ABNT, 2004b. 3p.

Albuquerque, J. A.; Argenton, J.; Fontana, E. C.; Costa, F. S.; Rech, T. D. Propriedades físicas e químicas de solos incubados com resíduo alcalino da indústria de celulose. Revista Brasileira de Ciência do Solo, v.26, p.1065-1073, 2002.

Albuquerque, J. A.; Medeiros, J. C.; Costa, A. da.; Rengel, M. Aplicação de resíduo alcalino na superfície de Cambissolos. Bragantia, v.70, p.888-898, 2011.

Almeida, H. C.; Ernani, P. R.; Albuquerque, J. A.; Macabô Júnior, J.; Almeida, D. Influência da adição de um resíduo alcalino da Indústria de papel e celulose na lixiviação de cátions em um solo ácido. Revista Brasileira de Ciência do Solo, v.32, p.1775-1784, 2008.

Almeida, H. C.; Silveira, C. B.; Ernani, P. R.; Campos, M. L. E.; Almeida, D. Composição química de um resíduo alcalino da indústria de papel e celulose (Dregs). Química Nova, v.30, p.1669-1672, 2007.

Calace, N.; Nardi, E.; Petrônio, B. M.; Pietroletti, M. Adsorption of phenols by papermill sludges. Environmental Pollution, v.118, p.315-319, 2002.

Cavalcanti, J. V. F. L.; Abreu, C. A. M. de; Motta Sobrinho, M. A. da. Preparação e utilização de uma argila esmectítica organofílica como adsorvente de fenol. Química Nova, v.32, p.2051-2057, 2009.

CFS-RS/SC - Comissão de Fertilidade do Solo - RS/SC. Recomendações de adubação e de calagem para os Estados do Rio Grande do Sul e de Santa Catarina. 4.ed. Passo Fundo: SBCS- Núcleo Regional Sul, 2005. 224p.

CONAMA - Conselho Nacional do Meio Ambiente. Resolução CONAMAn.397, de 3 de abril de 2008. Altera o inciso II do $\S 40$ e a Tabela X do $\$ 50$, ambos do art. 34 da Resolução do Conselho Nacional do Meio Ambiente-CONAMA n. 357, de 2005, que dispõe sobre a classificação dos corpos de água e diretrizes ambientais para o seu enquadramento, bem como estabelece as condições e padrões de lançamento de Brasília, 2008.

Corrêa, J. C.; Büll, T. L.; Crusciol, C. A. C.; Marcelino, R.; Mauad, M. Correção da acidez e mobilidade de íons em Latossolo com aplicação superficial de escória, lama cal, lodos de esgoto e calcário. Pesquisa Agropecuária Brasileira, v.42, p.1307-1317, 2007.

Costa, E. O.; Rizzi, N. E.; Silva, H. D.; Maeda, S.; Lavoranti, O. J. Percolação de poluentes em solos após aplicação de resíduos de fábrica de papel reciclado. Floresta, v.39, p.409-418, 2009.

Cunha, A. B. Estudo da contaminação por compostos fenólicos de uma área impactada por resíduo de areia de fundição. Porto Alegre: UFRGS, 2005. 133p. Dissertação Mestrado

Luchese, A. V.; Costa, A. C. S. da; Souza Júnior, I. G. Lixiviação de íons após a aplicação de resíduos orgânicos de uma indústria farmoquímica Revista Brasileira de Engenharia Agrícola e Ambiental, v.12, p.189-199, 2008.
Lunardi Neto, A.; Albuquerque, J. A.; Almeida, J. A.; Mafra, A. L.; Medeiros, J. C.; Alberton, A. Atributos físicos do solo em área de mineração de carvão influenciados pela correção da acidez, adubação orgânica e revegetação. Revista Brasileira de Ciência do Solo, v.32 p.1379-1388, 2008.

Mariot, E.; Weber, O. L. dos S.; Spadotto, C. A.; Dores, E. F. G. de C. Uso do índice LIX na previsão de lixiviação dos pesticidas metolacloro, endossulfam, clorpirifós, carbendazim e diuron. Pesticidas: Revista de Ecotoxicologia e Meio Ambiente, v.19, p.57-67, 2009.

Medeiros, J. C.; Albuquerque, J. A.; Mafra, A. L.; Batistella, F.; Grah, J. Calagem superficial com resíduo alcalino da indústria de papel e celulose em um solo altamente tamponado. Revista Brasileira de Ciência do Solo, v.33, p.1657-1665, 2009.

Nada, A. M. A.; El-Sakhawy, M.; Kamel, S. M. Infra-red spectroscopic study of lignins. Polymer Degradation and Sluhility, v.60, p.241 251, 1998.

Pacheco Júnior, A. C.; Souza, E. L.; Rocha Filho, G. N. da. Estudo experimental da capacidade de sorção e desorção de fenóis em solos da área da Albras - Barcarena/PA - Brasil. Geochimica Brasiliensis, v.19, p.37-47, 2005.

Pinheiro, A.; Moraes, J. C. S.; Silva, M. R. da. Pesticidas no perfil de solos em áreas de plantação de cebolas em Ituporanga, SC. Revista Brasileira de Ciência do Solo, v.5, p.533-538, 2011.

Rodrigues, G. D.; Silva, L. H. M. da; Silva, M. C. H. da. Alternativas verdes para o preparo de amostras e determinação de poluentes fenólicos em água. Química Nova, v. 33, p.1370-1378, 2010.

Santana, C. M.; Ferrera, Z. S.; Padróm, M. E. T.; Rodrigues, J. J. S. Methodologies for the extraction of phenolic compounds from environmental samples: New approaches. Molecules, v.14, p.298-320, 2009.

SAS - Institute INC.SAS 9.1.3 (TS1M3) for Windows Microsoft. Cary: SAS Institute Inc, 2007.

Silva, E. R. da; Assis, O. B. G. Avaliação de técnica eletroquímica na remoção de resíduos orgânicos em água com emprego de unidade em escala de laboratório. Engenharia Sanitária e Ambiental, v.9, p.193-196, 2004.

Singh, S.; Chandra, R.; Patel, D. K.; Reddy, M. M. K.; Rai, V. Investigation of the biotransformation of pentachlorophenol and pulp paper mill effluent decolorisation by the bacterial strains in a mixed culture Bioresource Technology, v.99, p.5703-5709, 2008.

Teixeira, J. B. Utilização de resíduos sólidos alcalinos de indústrias de celulose na correção da acidez do solo. Porto Alegre: UFRGS, 2003.105p. Dissertação Mestrado

Trigueiro R. de M. Efeito de "dregs e grits" nos atributos de um neossolo quartzarênico e na produção volumétrica de eucalipto. Botucatu: UNESP, 2006. 73p. Tese Doutorado

Wahyudiono, M. S.; Motonobu, G. Recovery of phenolic compounds through the decomposition of lignin in near and supercritical water. Chemical Engineering and Processing, v.47, p.1609-1619, 2008.

Wallberg, O.; Holmqvist, A.; Jonsson, A. S. Ultrafiltration of kraft cooking liquors from a continuous cooking process. Desalination, v.180, p.109-118, 2005.

WHO-IPCS - World Health Organization - International Programme on Chemical Safety - Environmental health criteria for phenol (161 ). First draft prepared by Ms G. K. Montizan: WHO, Printed in Finland, 1994. 21p. 